\title{
Robot-assisted septal myectomy for hypertrophic cardiomyopathy with left ventricular outflow tract obstruction
}

\author{
Zain Khalpey, MD, PhD, MRCS (Eng), ${ }^{\mathrm{a}}$ Lev Korovin, BS, ${ }^{\mathrm{a}}$ W. Randolph Chitwood, Jr, MD, FACS, FRCS, and \\ Robert Poston, MD, ${ }^{\mathrm{a}}$ Tucson, Ariz, and Greenville, NC
}

Hypertrophic cardiomyopathy is a relatively common disease caused by genetic mutations that disrupt the sarcomere components. Although frequent in younger patients, it can present from infancy to old age. Its natural history can include sudden cardiac death, arrhythmias, and heart failure. ${ }^{1}$ Severe heart failure symptoms can result from left ventricular outflow tract (LVOT) obstruction, with or without systolic anterior motion of the mitral valve apparatus. For patients with LVOT obstruction, the outflow tract pressure gradient can be reduced using interventional techniques that have included surgical septal myectomy and alcohol septal ablation. According to a recent metaanalysis, septal myectomy has been superior in terms of reducing the gradient and preventing persistent conduction abnormalities. $^{2}$

The initial reports of myectomy for symptomatic patients with LVOT obstruction described septal exposure by way of a left atriotomy and takedown of the anterior mitral leaflet. Given the challenge of septal visualization, this traditional approach was abandoned for the current standard, the Morrow procedure, which involves access to the ventricular septum by way of an aortotomy across the aortic valve. Two major limitations of both these procedures have been the required sternotomy and associated prolonged postoperative recovery.

Surgical robotics has been used to routinely access the mitral valve by way of a left atriotomy. Therefore, a similar approach could be used to reintroduce the transatrial, transmitral approach to the hypertrophic septum. We have described a septal myectomy performed with a lessinvasive, robot-assisted approach in a patient with recurrent symptomatic LVOT obstruction who had previously undergone an alcohol ablation procedure.

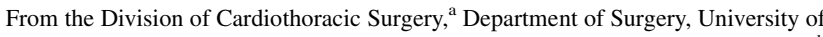
Arizona College of Medicine, Tucson, Ariz; and East Carolina Heart Institute, ${ }^{b}$ East Carolina University, Pitt County Memorial Hospital, Greenville, NC.

Disclosures: Authors have nothing to disclose with regard to commercial support.

Received for publication Sept 25, 2013; revisions received Dec 3, 2013; accepted for publication Dec 23, 2013.

Address for reprints: Zain Khalpey, MD, PhD, MRCS (Eng), Division of Cardiothoracic Surgery, Department of Surgery, University of Arizona College of Medicine, 1501 N Campbell Ave, No. 4302a, Tucson, AZ 85724 (E-mail: zkhalpey@surgery. arizona.edu).

J Thorac Cardiovasc Surg 2014;147:1708-9

0022-5223/\$36.00

Copyright (c) 2014 by The American Association for Thoracic Surgery

http://dx.doi.org/10.1016/j.jtcvs.2013.12.017
}

\section{SURGICAL TECHNIQUE}

The patient's preoperative echocardiogram demonstrated systolic anterior motion of the mitral valve chordate with an LVOT gradient of 20 to $30 \mathrm{~mm} \mathrm{Hg}$ that increased to $61 \mathrm{~mm}$ Hg with the Valsalva maneuver. The maximum septal thickness was measured at $16.5 \mathrm{~mm}$ using computed tomography. Moreover, the patient had class III heart failure symptoms despite maximal medical therapy.

After deflating the patient's right lung, we inserted 3 ports at the third, fifth, and seventh intercostal spaces. We docked the robot to those ports using a topographic approach similar to that described by Chitwood. ${ }^{3}$ After systemic heparinization, we instituted cardiopulmonary bypass using femoral artery and vein cannulation. With both lungs deflated, we used robotic instruments to open and tack the pericardium to the chest wall. We dissected Sondergaard's groove to separate the left and right atria and then induced cardioplegia using ascending aorta cannulation in an antegrade manner.

Next, we incised the left atrium and inserted the left atrial retractor. The mitral valve was normal on inspection. We opened the anterior leaflet (Figure 1,A) and identified the septum and aortic valve (Figure 1, $B$ ). The previously ablated portion of the septum was clearly visible by the extensive scarring. We removed 3 strips of the copiously scarred ablated septum, which lacked normal myocardial tissue (Figure 1,C). We reapproximated the anterior leaflet with Gore-Tex 5-0 suture (W. L. Gore \& Associates, Flagstaff, Ariz) and then tested the valve for leakage.

Finally, we closed the left atrium, removed the crossclamp, and performed de-airing maneuvers. Initially, we observed signs of a spontaneous rhythm; however, subsequently, complete heart block developed. Therefore, we paced the patient ventricularly, using a pacing wire to the inferior aspect of the right ventricle. The LVOT gradient was reduced; we no longer observed systolic anterior motion. The patient was successfully weaned off cardiopulmonary bypass. Postoperatively, the patient required placement of a permanent pacemaker for persistent complete heart block; however, she had returned to a normal sinus rhythm 1 month postoperatively. The immediate postoperative echocardiogram showed an LVOT gradient of $15 \mathrm{~mm} \mathrm{Hg}$. At her 4-month follow-up visit, we noted no significant intracavitary gradient. The postoperative septal thickness was $0.98 \mathrm{~cm}$, and the distance between the mitral-septal contact point and the aortic annulus was $1.0 \mathrm{~cm}$. 


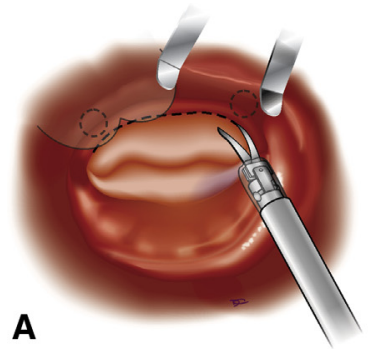

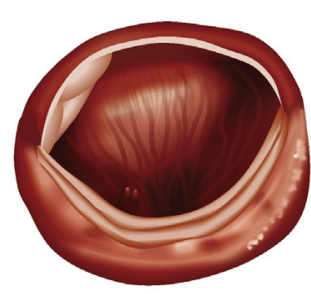

B

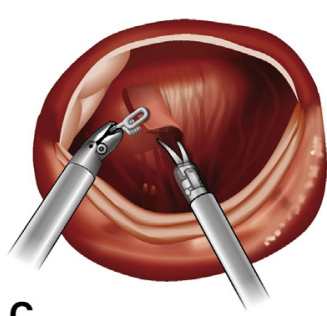

C

FIGURE 1. A, Opening the mitral valve anterior leaflet. Curved robotic scissors were used to incise the anterior leaflet, proceeding counterclockwise in a radial fashion from the right fibrous trigone to the left fibrous trigone. B, Exposure of the interventricular septum and aortic valve through the mobilized mitral valve anterior leaflet. C, Resection of the previously ablated fibrotic interventricular septum. The rectangular resected tissue was extended clockwise from near the left fibrous trigone to the nadir of the right coronary cusp.

\section{DISCUSSION}

The Morrow procedure uses a midline sternotomy, with the left ventricle and septum accessed by the aortic valve through a vertical aortotomy. ${ }^{4}$ The potential limitations of the procedure include small, but persistent, risks of an aortotomy (eg, postoperative bleeding, aortic dissection), difficulties with visualizing the surgical anatomy, and the risk of aortic valve damage (approximately $5 \%$ rate of moderate aortic regurgitation postoperatively ${ }^{5}$ ).

A robotic approach using the left atrium and across the mitral valve is an alternative and more direct route to the ventricular septum that can circumvent the limitations of the standard transaortic approach. The required robotic manipulation of the mitral valve for left ventricular septum access seems less risky than the transaortic route across the often friable aortic valve for provoking valvular damage.

Although additional studies are needed to evaluate the frequency of associated complications, our robot-assisted technique could be an acceptable alternative to the Morrow procedure.

The authors would like to thank Michael F. Teodori, MD, for surgical guidance in the operating room. Additional thanks are given to Katherine Stavoe and Kitsie Penick for assistance with manuscript preparation.

\section{References}

1. Maron BJ, Maron MS. Hypertrophic cardiomyopathy. Lancet. 2013;381:242-55.

2. Agarwal S, Tuzcu EM, Desai MY, Smedira N, Lever HM, Lytle BW, et al. Updated meta-analysis of septal alcohol ablation versus myectomy for hypertrophic cardiomyopathy. J Am Coll Cardiol. 2010;55:823-34.

3. Chitwood WR. Idiopathic hypertrophic septal obstruction: robotic transatrial and transmitral ventricular septal resection. Oper Tech Thorac Cardiovasc Surg. 2012; 17:251-60.

4. Morrow AG, Reitz BA, Epstein SE, Henry WL, Conkle DM, et al. Operative treatment in hypertrophic subaortic stenosis: techniques, and the results of pre and postoperative assessments in 83 patients. Circulation. 1975;52:88-102.

5. van der Linde D, Roos-Hesselink JW, Rizopoulos D, Heuvelman HJ, Budts W, van Dijk AP, et al. Surgical outcome of discrete subaortic stenosis in adults: a multicenter study. Circulation. 2013;127:1184-91.

\title{
Modified surgical approach to symptomatic hypertrophic cardiomyopathy with abnormal papillary muscle morphology: Septal myectomy plus papillary muscle repositioning
}

\author{
Marianna Redaelli, MD, Camillo Luca Poloni, MD, Samuele Bichi, MD, and Giampiero Esposito, MD, \\ Bergamo, Italy
}

\footnotetext{
From the Section of Cardiac Surgery, Department of Cardiovascular Disease, Cliniche Humanitas Gavazzeni, Bergamo, Italy.

Disclosures: Authors have nothing to disclose with regard to commercial support.

Received for publication May 3, 2013; revisions received Sept 27, 2013; accepted for publication Oct 6, 2013; available ahead of print Feb 9, 2014.

Address for reprints: Marianna Redaelli, MD, Istituto Clinico Humanitas Gavazzeni, via mauro Gavazzeni, Bergamo 24125, Italy (E-mail: marianna.redaelli@ gavazzeni.it).

J Thorac Cardiovasc Surg 2014;147:1709-11

$0022-5223 / \$ 36.00$

Copyright (c) 2014 by The American Association for Thoracic Surgery

http://dx.doi.org/10.1016/j.jtcvs.2013.10.085
}

Hypertrophic obstructive cardiomyopathy (HOCM) is considered a primary disease of cardiac muscle characterized by a diverse morphologic and clinical spectrum. ${ }^{1,2}$ The physiopathology of hypertrophic cardiomyopathy has been clarified by advanced echocardiographic and magnetic resonance imaging technologies (cardiac magnetic resonance imaging). With these advances, surgical management has also evolved, because the role of the mitral valve and subvalvular structures in causing 